\title{
THE REACTION OF DIABETIC BLOOD TO SOME OF THE ANILIN DYES.
}

BY V. A. LATHAM, M. D., D. D. S.

The importance of the clinical investigation of the blood is fast becoming an evident factor in the medical and chemical education of to-day, and it seems surprising that so many recent manuals pertaining to clinical methods should leave out the reaction of anilins with the blood in cases of diabetes mellitus. That, as yet, the work may be open to criticism, we do not doubt; but every microscopical student interested in the subject might at least endeavor either to improve our knowledge, or to disprove the value of the test by systematic examinations.

We usually find the statement made that to detect the difference between diabetic and non-diabetic blood, owing to the amount of sugar present in each, it is necessary to examine a large quantity of blood. This renders the investigation unpleasant to both physician and patient; and any method by which a satisfactory result can be obtained through using only a drop or two of blood will be very gladly accepted. Originality is not claimed in the methods here given, but I urge the further investigation of a method which seems to promise good results with very little trouble, and it is for this reason I send the slides and brief notes.

In blood examination, let us review the points to be carefully observed:

(a) Cleanliness of instruments, slides, covers and apparatus.

(b) Purity of dyes, which must be obtained from a reliable dealer, and should be especially designated for the particular study in hand.

(c) The employment of watery solutions, which should be filtered, as mould is liable to occur. 
(d) Even films and not too thick, except for the microscopic examination.

(e) Strictly following an author's method.

(f) Avoiding over-heating, either in degree or time.

(g) Preparation of control slides under exactly the same conditions.

In examining blood in cases of suspected diabetes, remember there is yet something indefinite in our knowledge regarding the pathologic conditions; this affection shares somewhat in the confusion incident to the study of kidney disease generally. Herein is a source of error, which may, perhaps, result in no reaction, even though the method and technique be faultless. It is unnecessary here to enter into a discussion of symptoms and nomenclature beyond stating that the factor of time (i. e. duration of the disease) is important in differentiating between glycosuria and true diabetes. The latter term applies only to that form in which the specific gravity is high, sugar excretion abundant, diuresis, thirst and other cardinal symptoms present. It is an interesting fact that not only does the blood react to anilins, but also the urine, showing that glucose decolorizes in a warm alkaline solution, in urinalysis. In making the blood test it is often an advantage to test the urine also. In fact, this must be done, unless the investigator is experienced in blood work, and I would suggest the phenylhydrazin test as modified by $\mathrm{R}$. T. Williamson, from Hoffmann and Ultzmann's work. It is a simple test, the reagents can be easily kept in powder, a short time only is required to make the examination, and it is possible to leave the specimen and look for the crystals when convenient. Permanent specimens may then be made of the large, fine, sulphuryellow needle crystals, by drying the deposit on a slide and mounting in canada balsam. A small amount even of albumen does not seem to invalidate the test, though it is best to remove all we can by filtering. The test does not show any crystals of phenylglucosazone in normal urine. It gives no reaction with uric acid, creatinin, hippuric acid, pyrocatechin, as gotten by Fehling's method. The objection has been raised 
that the test is too sensitive for clinical work, and that if glycuronic acid be present, similar crystals are formed. This is the case, if Moritz's method is used, but not if Williamson's be carefully followed.

The blood shows the color to be slightly darker than is the case with normal blood. The reaction is alkaline, even if coma be present, and is best tested by the papers especially devised by Haycraft and Williamson. The percentage of water varies but is usually slightly diminished. The specific gravity, though variable, is mostly increased. The number of red corpuscles also varies, though usually the hemoglobin is greater than normal, which is a differentiating point between many chronic ailments and saccharine diabetes. The leucocytes show no definite change in their proportion, though Professor Limbeck says leucocytosis accompanying digestion is frequently so well-marked in severe cases as to be a distinguishing mark of diabetes.

To prepare films for examinations, any one of several methods may be used. Among the best are

(a) Cover-glass films,

(b) Slide-films, and

(c) Dr. Manson's modification of the latter.

(a) Cover-films are readily made by placing two square covers diagonaily across one another with a drop of blood between, and slipping them apart to spread the blood.

Or a cover can, after a little practice, be passed lightly over a drop of blood in such a manner as to barely touch its surface and leave a film thinly spread.

(b) Slide-films may be prepared by spreading a drop which has been put about one-third from the end of the slide, using a second slide to spread the drop by pushing it over the latter like a plane.

Or, slides may be lightly drawn, one over the other, starting from the center or a little beyond; this method is not so satisfactory if the specimens are intended for microscopic examination, as the film is at the end of the slide and inconvenient to examine over the circular opening in the stage. 
(c) Dr. Patrick Manson's Method is a modification of the slide-film described above. Its details are as follows: Prick the finger after thoroughly cleansing it, wipe off the first drop, using the next for films. Have ready some strips of smooth gutta-percha tissue, or the thinnest tissue paper, three-fourths of an inch wide and an inch and a half long. Apply one of these strips to the exuded blood, about midway, and at once place the charged strip, blood surface down, upon a well-cleaned glass slip, wait a second or two till the blood spreads out, then draw the gutta-percha or paper by the uncharged end along the glass. A very thin film of blood, with evenly disposed corpuscles, is secured, and at least three or four slips may be prepared from the one charging if neatly and quickly done. Let the slips dry, and they may be stained and examined at any later period that is convenient. The use of tissue paper is recommended, for the absorption of blood in the paper allows the spreading of a large number of films and retards coagulation longer than any other method. Personally I prefer a strip of stout notepaper held with the thumb and first two fingers so it curves part way around the index finger. The curved end is used to take up the blood, and then drawn lightly along the slide at an acute angle, leaving an even film with the corpuscles thinly and regularly distributed.

For the preservation of mounts of blood, especially if stained with methylen blue, iodine gum will be found useful, as the stained specimens fade so easily in the balsam; even such objects as the plasmodiae show nicely in the gum.

The films must now be fixed, which may be done by any one of the following methods:

(a) Absolute Alcohol for ten minutes.

(b) Absolute Alcohol and Ether, equal parts-the maximum time that allowed sharp staining I found to be twenty-five minutes.

(c) Formol, 10 per cent.

(d) Bichloride of Mercury, a method in which care must be used to avoid crystalline deposits, and not recommended for diabetic blood. 
(e) Heat incubation or by Ehrlich's copper plate.

(f) Gulland's method, the formula being:

Saturated solution of eosin in absolute alcohol ...25 c. c.

Pure ether.......................

Sol. of mercury bichloride in abs. alc. ( 2 grms. in

10 c. c. $\ldots \ldots \ldots \ldots \ldots \ldots \ldots \ldots$ drops or so.

The last method is useful as a time-saver, for the slides are dropped in the fluid while the films are wet, or if covers are used the films are quickly immersed in the solution before drying occurs, 5cc. to $10 \mathrm{cc}$. being sufficient for four films. Three minutes are sufficient to fix the films, though immersion for twenty-four hours will not harm them. Wash in water very thoroughly and counterstain if desired. (Sputum and pus can also be stained and fixed by Gulland's method.)

To detect Glycogen in the Blood.-Prepare the films or slides, dry and mount in iodine gum, made as follows:

Iodine.................. 1 part

Potassic Iodide ............. 3 parts

Distilled Water, to which an excess of pure

Gum Arabic has been added....100 parts.

Glycogen is detected in two forms. (1) In the multi-nuclear neutrophilic leucocytes, as intra-cellular glycogen. (2) As free extra-cellular glycogen, which arises from the degeneration of the leucocytes. In normal blood only the extra-cellular glycogen can be recognized with certainty by the action of iodine in cover preparations. But in diabetic blood minute specks of glycogen, stained deep brown with iodine can be seen distinctly in some leucocytes, and the amount of extracellular glycogen is two or three times more than in cover preparations of normal blood.

Ludwig Bremer gives a very simple test to distinguish diabetic from non-diabetic blood, by its action in decolorizing methylen blue. [Methyl blue is absolutely useless in this work; the pure "medicinal" or "Methylen blau nach Ehrlich" giving the best results. I understand Dr. Rotch advises Grïbler's methylen blue, soluble in alcohol, as the best.] R. T. Williamson uses the same anilin-reaction in a different 
manner. There are several modifications of Bremer's method, and for convenience we shall describe two, the microscopic and the macroscopic.

(a) The Microscopic Method.-Make thin even cover films of some diabetic and normal blood. Fix with equal parts of absolute alcohol and ether; it is recommended to place the fixative in a vessel over a water-bath and boil for four minutes. Then stain, in a specially prepared solution made as follows: Take saturated watery solutions of eosin and methylen blue; mix in equal parts. A precipitate forms, which should be filtered off, washed, dried and reduced to powder. A $\frac{1}{24}$ part of eosin and $\frac{1}{6}$ of methylen blue are added. From 0.025 grm. to $0.05 \mathrm{grm}$. of this mixture is dissolved in $10 \mathrm{grms}$. of a 33 per cent. solution of alcohol. Stain for four or five minutes in a warm place, wash in distilled water rapidly, dry in air and mount. The diabetic film, or glycosuric blood corpuscles are stained a sap or bluish-green. Non-diabetic blood is a reddish violet or madder color. Le Goff used a watery solution of eosin mixed with a saturated watery solution of methylen blue (proportions not given, but possibly equal parts); the resulting precipitate he washed and dried. Five grams of this substance he directs to be dissolved in twenty to twenty-five grams of alcohol ( 30 per cent.). Filter the solution. Covers are heated in an incubator for two hours at a temperature of $120^{\circ} \mathrm{C}$., then stained with the above solution, washed in distilled water, dried with bibulous paper and mounted in xylol-balsam. The red corpuscles of normal blood stain variously from a clear purplish rose-color to a dark maroon, while diabetic red corpuscles stain pale green, yellowish-green, or are unstained. Nuclei of white cells are blue, and are the same in normal and in diabetic blood. He records some very interesting color-reactions of diabetic blood. Bremer prefers the blue to be free from zinc, while Lépine prefers zinc to be present. The former urges using a fresh solution, added to the water just before use. Lépine has described a similar reaction in leukaemia, but it is quite likely that glycosuria was also present. 
A modification of Bremer's method is to use a 2 per cent. solution of methylen blue for two minutes, then stain for ten seconds in a 0.125 per cent. solution of eosin. Keeping all the precautions of Bremer in view it was found that in every case of diabetes in which the amount of sugar in the urine was more than 2 per cent. the blood gave the characteristic reaction. Even in a case where dieting had caused the sugar to disappear, the reaction persisted. No reaction is found in the blood of severe anaemia. The blood plasma is not essential in producing the reaction. If $5 \mathrm{ccm}$. of blood be taken from a vein of a diabetic patient and placed in a centrifuge, the corpuscles are readily separated from the plasma. The corpuscles, after being washed in normal saline solution until the washings give no trace of sugar, still give the Bremer reaction.

(b) The Macroscopic method also shows that the red blood corpuscles which stain normally with acid stains, in diabetes require basic dyes.-Smear evenly upon two slides, about $\frac{1}{2}$ or $\frac{1}{3}$ their length, a tolerably thick film of blood-normal blood on one slide and diabetic blood upon the other. Heat in an incubator six to ten minutes at a temperature of $135^{\circ} \mathrm{C}$. [In a personal note, Dr. Bremer advises that the flame be removed when the temperature reaches $130^{\circ} \mathrm{C}$, $135^{\circ} \mathrm{C}$. being the optimum and $129^{\circ} \mathrm{C}$. the lowest point at which the test is reliable. Heating for over ten minutes also renders the film valueless.] Now stain in a 1 per cent. aqueous solution of one or more of the stains on the following page.

The reaction is possibly due to the alkalinity, but as yet is imperfectly understood. Almost any histological stain will do to differentiate diabetic from normal blood, provided that according to its chemical constitution it has an affinity either for non-diabetic or diabetic red blood corpuscles.

The blood reaction obtained by methylen blue is of value in distinguishing the coma of diabetes from other forms of coma, especially in cases, seen for the first time, in which the patient without history or friends, is brought to the hospital in an unconscious condition. Where no urine can be obtained, 


\begin{tabular}{|c|c|c|c|c|}
\hline & & & REACTION & F BLOOD \\
\hline & & & NORMAL & DIABETIC \\
\hline (a) Congo & Red. & $\begin{array}{l}1 \text { per cent. Aque- } \\
\text { ous Sol. for } 11 / 2 \\
\text { to } 2 \text { min. Wash } \\
\text { in Dist. } \mathrm{H}_{2} \mathrm{O} \text { rap- } \\
\text { idly, dry. }\end{array}$ & Stained Red. & $\begin{array}{l}\text { Not stained or } \\
\text { only indiffer- } \\
\text { ently. }\end{array}$ \\
\hline $\begin{array}{r}\text { (b) Methy } \\
\text { Blu }\end{array}$ & $\begin{array}{l}\text { len } \\
\text { e. }\end{array}$ & "، & $\begin{array}{l}\text { “ Greenish- } \\
\text { Blue. }\end{array}$ & 6 \\
\hline $\begin{array}{l}\text { (c) Biebri } \\
\text { let. }\end{array}$ & h Scar- & & Unstained. & $\begin{array}{l}\text { Deeply stain- } \\
\text { ed. }\end{array}$ \\
\hline (d) Ehrlic & a-Biondi. & $\begin{array}{l}2-3 \text { min. (1 per } \\
\text { cent.) }\end{array}$ & Violet. & Orange. \\
\hline & - & -BEAUTIFUL C & NTRASTS BY- & \\
\hline Double & $\begin{array}{l}\text { Methyl } \\
\text { Green. }\end{array}$ & $\begin{array}{l}1 \text { per cent. Aque- } \\
\text { ous Sol. } 11 / 2 \text { to } 2 \\
\text { min. Wash in } \\
\text { Dist. } \mathrm{H}_{2} \mathrm{O} \text {. }\end{array}$ & & $\begin{array}{l}\text { Green, deeper } \\
\text { than in normal } \\
\text { blood. }\end{array}$ \\
\hline $\mathrm{ng}$ & Eosin. & $\begin{array}{l}1 / 8-1 \text { per cent. } \\
\text { Aqueous Sol. } 10 \\
\text { sec. Wash, dry. }\end{array}$ & Eosin Color. & Green. \\
\hline & $\begin{array}{l}\text { Methy- } \\
\text { len } \\
\text { Blue. }\end{array}$ & & $\begin{array}{l}\text { Red Corpuscles } \\
\text { Deep Brown or } \\
\text { Purple. }\end{array}$ & $\begin{array}{l}\text { Red Corpus- } \\
\text { cles }\end{array}$ \\
\hline & Eosin. & & & $\begin{array}{l}\text { Green or } \\
\text { Greenish- } \\
\text { Yellow. }\end{array}$ \\
\hline
\end{tabular}


the blood test furnishes an accurate and ready means of diagnosis.

Williamson's Modification. - Thoroughly clean a narrow test tube (a wide one gives too large an area for the action of oxygen), and place in it $40 \mathrm{ccm}$. of distilled water. With a Southall's $1 \mathrm{ccm}$. tube take $20 \mathrm{ccm}$. of blood from the finger and blow it gently into the water. Should it stick to the side, carefully shake it to the bottom. Then add $1 \mathrm{ccm}$. of a 1:6000 water solution of methylen blue, and then add $40 \mathrm{ccm}$. of a solution of potassium hydrate. Mix well by shaking. Also make a control specimen of normal blood. We see the fluid in each tube has a fairly deep blue color. Place them in a beaker and heat in a water-bath until the boiling point is reached. Boil four minutes. The diabetic blood is now changing from a deep blue to a dirty pale yellow, almost the color of normal urine. The normal blood remains blue, or bluish-green, sometimes a pale violet, but never decolorizes, i. e., never loses its blue color. N. B.-The tubes must be kept quite still in the water-bath, as shaking causes decolorization of methylen blue by oxidation from the atmosphere, and the blue may return. Severe cases will decolorize a methylen blue solution of double strength, i. e., 1:3000. No other disease, I believe, has yet been found that will decolorize the blue. The reaction is probably due to excess of grape-sugar, as this substance readily removes color from a warm alkaline solution of methylen blue as seen in the urine test.

In conclusion: Anilin methylen blue is also used for estimating the amount of sugar in the blood, and as a test for glucose in the urine. Safranin 1:1000 is also used, and others of the same group.

Possible failure to secure the reaction may resuit from neglect of the precautions enjoined, from use of impure dyes, from experiment on cases not truly diabetic, or from insufficient experience on the part of the worker. But to condemn a method without repeated tests by a sufficient number of competent observers is certainly wrong. The anilin reaction of blood in diabetes may in time prove as helpful as the Widal 
reaction in typhoid fever, which, though not, as we all hoped it would be, a sure and early positive diagnosis in typhoid fever, is valuable as one determining factor in diagnosis. Even in these days of comparative uncertainty, a blood examination is essential to a modern practitioner's investigation of a supposed case of typhoid; and it may prove an equal, if not a better aid, in the study of diabetes.

808 Morse Ave., Chicago, Ill.

\section{BIBLIOGRAPHY.}

ALlen.-Chemistry of Urine.

VoN JaKsCH.-Clinical Diagnosis.

RIEDER.-Blood Atlas, \&c.

LIMBECK.-Diseases of Blood, etc.

Stengel.-Twentieth Century Medicine.

OsLER.-Pepper's American Text book of Medicine.

Loewy.-British Medical Journal, Vol. 1, June, 1898.

Coles, A. C.-On Blood Diseases.

Bremer. - Centralblatt für Med., June 5, 1897.

N. Y. Med. Jour., Mar. 7, 1896.

Medical News, Philadelphia, Feb. 9, 189.5.

- British Med. Jour., July 3, Aug. 28, 1897.

Liter Jet. Le Goff.-Paris, 1897, p. 44.

LÉPine et Lyonnet.-Lyon, Med., 1896, Vol. 82.

Lyon, Med., 1896-1897.

R. Maguire.-Fowler's Dictionary of Medicine.

Williamson.-Centralblatt für Wiss. Med., Berlin, 1894.

Hutchison and Rainy.-Clinical Diagnosis, 1888.

Gulland.-British Med. Journal, March, 1897. 


\section{$2 \mathrm{BHL}$ Biodiversity Heritage Library}

Latham, V A. 1900. "The Reaction of Diabetic Blood to Some of the Anilin Dyes." Transactions 21, 31-40.

View This Item Online: $\underline{\text { https://www.biodiversitylibrary.org/item/86839 }}$

Permalink: https://www.biodiversitylibrary.org/partpdf/90942

\section{Holding Institution}

University of Toronto - Gerstein Science Information Centre

\section{Sponsored by}

University of Toronto

\section{Copyright \& Reuse}

Copyright Status: Not provided. Contact Holding Institution to verify copyright status.

This document was created from content at the Biodiversity Heritage Library, the world's largest open access digital library for biodiversity literature and archives. Visit BHL at https://www.biodiversitylibrary.org. 